\title{
CONTROLE PÓS-COLHEITA DA ANTRACNOSE DO PIMENTÃO PELA LEVEDURA Rhodotorula glutinis
}

\author{
POST-HARVEST CONTROL ANTHRACNOSE IN PEPPER BY YEAST Rhodotorula \\ glutinis
}

\author{
Gisely Santana de FRANÇA ${ }^{1}$; Rejane Rodrigues da COSTA e CARVALHO ${ }^{2}$; \\ Rejane Pereira NEVES ${ }^{3}$; Emmanuelle Rodrigues ARAUJO ${ }^{4}$; Delson LARANJEIRA ${ }^{5}$ \\ 1. Mestranda, Fitopatologia, Universidade Federal Rural de Pernambuco - UFRPE, Recife, PE, Brasil; 2. Professora, Doutora, \\ Fitotecnia, UFRPE, Recife, PE, Brasil; 3. Professora, Doutora, Programa de Pós-Graduação em Biologia de Fungos, Universidade \\ Federal de Pernambuco - UFPE, Recife, PE, Brasil; 4. Doutoranda em Fitopatologia, UFRPE, Recife, PE, Brasil; 5. Professor, Doutor, \\ Programa de Pós-Graduação em Fitopatologia, UFRPE, Recife, PE, Brasil. delson@ depa.ufrpe.br
}

RESUMO: Considerando as perdas causadas em pós-colheita pela antracnose no pimentão e à ineficácia das medidas de controle atualmente utilizadas, este trabalho teve por objetivo estudar a potencialidade antagônica in vitro e in vivo de quinze isolados de leveduras à Colletotrichum sp., agente causal da antracnose em pimentão. Foi calculada a porcentagem de inibição do crescimento do fungo dos tratamentos em relação à testemunha nos testes in vitro e determinado o tamanho da área lesionada em frutos através da mensuração do comprimento da lesão em dois sentidos diametricamente opostos nos testes in vivo. As leveduras que obtiveram o melhor resultado no controle da antracnose foram identificadas através de características macroscópicas, microscópicas, fisiológicas, bioquímicas e por taxonomia molecular, sendo os isolados de levedura 13E e 13A1, os que obtiveram as melhores respostas no controle do fitopatógeno tanto in vitro quanto in vivo, identificados como pertencentes à espécie Rhodotorula glutinis.

PALAVRAS-CHAVE: Colletotrichum sp. Doenças pós-colheita. Controle biológico de doenças

\section{INTRODUÇÃO}

A antracnose, doença causada por fungos do gênero Colletotrichum, é uma das doenças de maior importância para as solanáceas, como o pimentão (Capsicum annum). Os sintomas da antracnose podem ocorrer durante o desenvolvimento da cultura no campo ou em pós-colheita, mas somente os frutos exibem sintomas típicos (LOPES; ÁVILA, 2003), que são caracterizados pela ocorrência de depressão circular de diâmetro variável, com a presença de uma massa alaranjada de esporos no centro das mesmas quando sob alta temperatura (TOZZE JÚNIOR et al., 2006). Em condições de temperatura amena a quente e chuvas frequentes e na ausência de controle adequado, os prejuízos podem chegar a $100 \%$ (KUROZAWA et al., 2005; AZEVEDO et al., 2006).

No Brasil, a antracnose do pimentão tem sido atribuída a C. gloeosporioides (LOPES; ÁVILA, 2003; KUROZAWA et al., 2005; AZEVEDO et al., 2006; TOZZE JÚNIOR et al., 2006), sendo este, também, o principal agente da antracnose do pimentão em Pernambuco (XAVIER FILHA; MICHEREFF, 2006).

A aplicação de fungicidas é, há muitos anos, o mais difundido método de controle da antracnose do pimentão no Brasil. Entretanto, a adoção contínua do controle químico pode acarretar o surgimento de patógenos resistentes aos produtos utilizados, além da contaminação de alimentos e do ambiente, intoxicação de homens e animais, ressurgimento de algumas doenças e de outras, antes consideradas secundárias, tornando-se importantes (GHINI; KIMATI, 2000). A necessidade de métodos mais seguros, eficientes, econômicos e não poluentes têm estimulado a busca de métodos de controle de doenças de plantas alternativos ao uso de produtos químicos (STANGARLIN et al., 1999). Neste contexto, o controle biológico utilizando microrganismo antagonista tem sido uma alternativa ao uso de fungicidas sintéticos, com considerável sucesso no controle de doenças de pré e pós-colheita (JANISIEWICZ; KORSTEN, 2002).

Uma variedade de microrganismos antagonistas vem sendo utilizada para o controle de diferentes patógenos, em frutos e hortaliças (FRAVEL, 2005). Entre estes organismos, as leveduras têm sido relatadas como agentes de controle biológico eficazes no controle de fitopatógenos (VALDEBENITO-SANHUEZA, 2000; QING; SHIPING, 2000; IRTWANGE, 2006). Essas podem atuar sobre os fitopatógenos através de antibiose, parasitismo, pela competição por nutrientes (BETTIOL, 1991) ou podem induzir a resistência.

Considerando as perdas causadas em póscolheita pela antracnose em pimentão e à ineficácia 
das medidas de controle atualmente utilizadas, este trabalho teve por objetivo avaliar a potencialidade antagônica in vitro e in vivo de isolados de leveduras à Colletotrichum sp., agente causal da antracnose em pimentão (Capsicum annuum L.).

\section{MATERIAL E MÉTODOS}

Os experimentos foram conduzidos no Laboratório de Fungos do Solo da Universidade Federal Rural de Pernambuco e no Laboratório de Micologia da Universidade Federal de Pernambuco.

\section{Isolamento do fitopatógeno e preparo do inóculo}

Frutos de pimentão, berinjela e folhas de tomateiro com sintomas de antracnose foram coletados em áreas de cultivo orgânico do município de Chã Grande-PE e enviados ao Laboratório de Fungos de Solo da Universidade Federal Rural de Pernambuco (UFRPE) para que se procedesse ao isolamento.

Fragmentos da área lesionada ou massa de esporos foram depositados em placas de Petri contendo meio BDA (batata-dextrose-ágar) e incubadas por 8 dias à temperatura de $25 \pm 2^{\circ} \mathrm{C}$ sob fotoperíodo de 12 horas. Posteriormente, foram realizados o isolamento e a repicagem dos microrganismos para tubos de ensaio contendo meio BDA os quais foram mantidos em condição de laboratório para posterior utilização nos testes de patogenicidade.

As suspensões fúngicas foram preparadas pela adição de $20 \mathrm{~mL}$ de água destilada esterilizada (ADE) ao meio de cultura contendo colônias de Colletotrichum sp. com 8 dias de idade e posterior raspagem com alça de Drigaslki e filtragem em camada dupla de gaze esterilizada. Os inóculos foram ajustados à concentração de $1 \mathrm{x} \quad 10^{6}$ esporos/mL.

\section{Isolamento das leveduras e preparo das suspensões}

Discos de $11 \mathrm{~mm}$ de diâmetro foram retirados da casca de frutos sadios de pimentão com um furador e cinco desses colocados em tubo de ensaio contendo $10 \mathrm{~mL}$ de água de torneira esterilizadas (ATE) e cloranfenicol na concentração de $50 \mathrm{mg} / \mathrm{L}$. Os tubos foram submetidos à agitação em banho de ultrassom por 15 minutos e no "vórtex" por 30 segundos. Posteriormente foi realizada a diluição da solução para $10^{-1}$, da qual foram retiradas alíquotas de $0,1 \mathrm{~mL}$, que foram uniformemente distribuídas em placas de Petri contendo meio de cultura Sabouraud-dextrose-ágar (DAS modificado) suplementado com extrato de levedura e cloranfenicol. As placas foram incubadas à temperatura de $25 \pm 2^{\circ} \mathrm{C}$ por 72 horas. Os isolados puros obtidos foram repicados em tubos de ensaio contendo o meio DAS modificado e conservados em óleo mineral.

As suspensões de leveduras utilizadas nos teste de biocontrole foram preparadas pela da adição de $20 \mathrm{~mL}$ de ADE à superfície do meio contendo colônias com 48 horas de crescimento, seguida da raspagem com alça de Drigalski. Alíquotas de $1 \mathrm{~mL}$ das suspensões foram transferidas individualmente para tubos de ensaio contendo $9 \mathrm{~mL}$ de água destilada esterilizada e submetidas à agitação em vórtex. A concentração das suspensões foi ajustada para $1 \times 10^{8}$ células $/ \mathrm{mL}$.

\section{Antagonismo in vitro de leveduras a Colletotrichum sp.}

Foram utilizados quinze isolados de leveduras. Alíquotas de $100 \mu \mathrm{L}$ das suspensões de leveduras foram depositadas no centro de placas de Petri contendo meio BDA e espalhados uniformemente com alça de Drigalski. Após duas horas, discos de $0,5 \mathrm{~mm}$ de diâmetro contendo estruturas de Colletotrichum sp. foram depositados no centro das placas. O delineamento usado foi inteiramente casualizado, onde cada tratamento foi composto de cinco repetições, sendo cada repetição representada por uma placa de Petri. As placas foram mantidas à temperatura de $26 \pm 2^{\circ} \mathrm{C}$ e fotoperíodo de 12 horas por sete dias.

As avaliações foram realizadas diariamente, através de medições do diâmetro das colônias em dois eixos ortogonais (média das duas medições diametricamente opostas), iniciando-se 24 h após o preparo das placas e sempre no mesmo horário, até que um dos tratamentos atingisse o diâmetro total da placa de Petri. Foram realizadas avaliações, calculando-se a porcentagem de inibição do crescimento do fungo dos tratamentos em relação à testemunha, utilizando-se a fórmula:

PIC $=\underline{(\text { diâmetro da testemunha }- \text { diâmetro do tratamento })} \times 100$ diâmetro da testemunha

Os dados obtidos nesse estudo foram submetidos à análise de variância, e as médias comparadas pelo teste de Scott-Knott a 5\% de probabilidade.

\section{Antagonismo in vivo de leveduras sobre Colletotrichum sp.}

Foram utilizados os mesmos isolados de leveduras do teste in vitro. Frutos sadios no estágio de maturação comercial, foram lavados e desinfestados pela imersão em $\mathrm{NaClO} 0,05 \%$ por cinco minutos. Cada fruto foi marcado na superfície 
em pontos equidistantes, onde foram efetuados ferimentos de aproximadamente $3 \mathrm{~mm}$ de profundidade com uma almofada com alfinetes desinfestados e depositados $100 \mu \mathrm{L}$ das suspensões das leveduras na concentração de 1,0 x $10^{8}$ células $/ \mathrm{mL}$. Após a inoculação, os frutos foram mantidos por 24 horas em câmara úmida constituída de placas de Petri envolvidas por sacos plásticos contendo chumaços de algodão umedecidos com ADE. Após uma hora de câmara úmida, foi depositado em cada ferimento $50 \mu \mathrm{L}$ da suspensão do inóculo do fitopatógeno ( $1 \times 10^{6}$ conídios $/ \mathrm{mL}$ ).

A testemunha relativa consistiu de frutos de pimentão com ferimentos inoculados com o patógeno e tratados com $\mathrm{ADE}$, enquanto que a testemunha absoluta foi constituída por frutos com ferimentos sem a inoculação do patógeno e tratados com ADE.

A avaliação ocorreu ao oitavo dia após a inoculação, determinando-se o tamanho da área lesionada através da mensuração do comprimento da lesão em dois sentidos diametricamente opostos. $\mathrm{O}$ delineamento experimental foi inteiramente casualizado com dez repetições, sendo cada repetição constituída por um fruto. Os dados obtidos nesse estudo foram submetidos à análise de variância, e as médias comparadas pelo teste de Scott-Knott a 5\% de probabilidade.

\section{Identificação dos isolados de leveduras utilizados}

A identificação das leveduras foi realizada através de características macroscópicas, microscópicas, fisiológicas e bioquímicas (KREGER VAN RIJ, 1984; BARNETT et al., 2000; LACAZ et al., 2002).

\section{Características macroscópicas}

Foram observadas a textura, produção de pigmentos e o tempo de crescimento das leveduras.

\section{Características microscópicas}

Foram observadas as estruturas somáticas (produção de pseudo-micélio e/ ou micélio verdadeiro) e reprodutivas (formação de blastoconídios, artroconídios e estruturas sexuadas) das leveduras ao microscópio de luz.

\section{Características fisiológicas e bioquímicas}

\section{Assimilação de compostos de carbono}

Após $72 \mathrm{~h}$ de crescimento das colônias foi realizada uma suspensão de cada levedura em solução de extrato de levedura a $0,1 \%$ de acordo com a escala 0,5 de MacFarland. As suspensões foram transferidas para placas de Petri e misturadas ao meio $\mathrm{C}$, isento de fontes de carbono. Após homogeneização e a posterior solidificação do meio, foi adicionado diferentes carboidratos in natura em pontos equidistantes. As culturas foram incubadas à $25^{\circ} \mathrm{C}$. A leitura foi realizada a cada 24 horas por 3 dias consecutivos. A assimilação de determinada fonte de carbono é observada pela formação de um halo no local.

\section{Assimilação de compostos de nitrogênio}

O procedimento é semelhante ao teste de assimilação de compostos de carbono, sendo neste caso utilizado o meio $\mathrm{N}$, isento de fontes de nitrogênio, em substituição ao meio $\mathrm{C}$ e em seguida foi adicionado diferentes fontes de nitrogênio.

\section{Fermentação de compostos de carbono}

Com a mesma suspensão de leveduras, foi verificada a capacidade de utilização de carboidratos em anaerobiose utilizando-se tubos de ensaio contendo em seu interior um tubo de Durham invertido. Em cada tubo preenchido com solução de carboidrato a $4 \%$ adicionou-se $100 \mu \mathrm{L}$ da suspensão. Os tubos foram incubados à temperatura de $25^{\circ} \mathrm{C}$ e a leitura foi realizada a cada $24 \mathrm{~h}$ por 10 dias consecutivos. A fermentação de determinada fonte de carbono é observada pela produção de gás carbônico no interior do tubo de Durham.

\section{Produção de urease}

Após crescimento de 72h, cada levedura foi semeada no meio Agar uréia de Christensen e incubadas à $25^{\circ} \mathrm{C}$ por 5 dias. A produção de urease é sinalizada pelo indicador de $\mathrm{pH}$ vermelho de fenol, que muda a coloração do meio de amarelo para o vermelho.

\section{Taxonomia molecular}

Os isolados foram incubados em meio de cultura YPD (extrato de levedura1\%, peptona de carne $2 \%$ e D-glucose $2 \%$ ) por 16 horas a $300^{\circ} \mathrm{C}$. As amostras homogenizadas foram transferidas para microtubos de $1,5 \mathrm{~mL}$ e centrifugadas por 3 minutos a $10000 \mathrm{rpm}$. Após a centrifugação o sobrenadante foi descartado e $600 \mu \mathrm{L}$ de tampão de extração (TrisHCl pH8,0 200mM, EDTA pH 8,0 25mM, $\mathrm{NaCl} 250 \mathrm{mM}$, SDS $1 \%$ ) foi adicionado para a lise de células, seguido de incubação a $65^{\circ} \mathrm{C}$ por 30 minutos com agitação por inversão a cada 10 minutos. Posteriormente, foram adicionados $600 \mu \mathrm{L}$ de clorofane (fenol, clorofil 1:1) e os tubos centrifugados a $13000 \mathrm{rpm}$ por 15 minutos. Da fase aquosa foram retirados $500 \mu \mathrm{L}$ e transferidos para novos microtubos aos quais foram acrescentados igual volume de clorofil (clorofórmio, álcool 
isoamílico 24:1) e centrifugados a $13000 \mathrm{rpm}$ por 15 minutos. Novamente, $400 \mathrm{ul}$ da fase aquosa foram transferidos para outros microtubos aos quais foram adicionados $800 \mu \mathrm{L}$ de álcool absoluto gelado e incubados por 2 horas a $-200^{\circ} \mathrm{C}$ para precipitação do DNA. A seguir as amostras foram centrifugadas a $13000 \mathrm{rpm}$ por 15 minutos e o sedimento lavados com álcool a $70 \%$, secados em estufa a $370^{\circ} \mathrm{C}$ e ressuspendido em $100 \mu \mathrm{L}$ de tampão TE.

Para identificação das leveduras foi utilizada a comparação das sequências de rDNA, onde a mistura de reação continha os primers específicos para a região $\mathrm{D} 1 / \mathrm{D} 2$ da região $26 \mathrm{~S}$ rDNA. Os primers utilizados para esta reação foram o NL-1 (5'-GCATATCAATAAGCGGAGGAAAAG-3') e NL-4 (5'-GGTCCGTGTTTCAAGACGG-3'). Além disso, os primers para a região ITS (Espaçadors Internos Transcritos) ITS1 (5'GGTCCGTGTTTCAAGACGG-3') e ITS4 (5'-TC CTCCGCTTATTGATATG-3'), foram também utilizados para alcançar altos níveis de separação intraespecífica. Os produtos de PCR foram separados através de eletroforese em gel de agarose a $0,8 \%(\mathrm{P} / \mathrm{V})$. As bandas foram coradas com brometo de etídio e fotografadas em um transluminador de luz ultravioleta. Os produtos de PCR foram purificados usando o "kit" de purificação QIA-quik (QIAGEN, Alemanha). As sequências foram alinhadas e comparadas com aquelas já depositadas no NCBI utilizando a ferramenta BLAST (NCBI BLAST: Bethesda, MD,USA).

\section{RESULTADOS E DISCUSSÃO}

Os isolados 11A2, 7D2, 13E e 13A1 foram os mais eficientes no controle in vitro de Colletotrichum sp. (Tabela 1). No experimento in vivo, os isolados de leveduras 13E, 13A1, 11E2 e $11 \mathrm{E} 1$ foram os mais eficientes em inibir $\mathrm{o}$ crescimento do patógeno nos frutos de pimentão (Tabela 1).

O estudo do antagonismo in vivo foi crucial na escolha do melhor agente de biocontrole, uma vez os testes in vitro identificam principalmente os antagonistas que são produtores de antibióticos (DROBY et al, 2009) e não refletem o ambiente nutricional do local da lesão no hospedeiro (MARI et al, 2012).

Tabela 1. Porcentagem de inibição do crescimento micelial (PIC) de Colletotrichum sp. e diâmetro da lesão de frutos de pimentão inoculados com o fungo e tratados com leveduras.

\begin{tabular}{|c|c|c|}
\hline Isolados de leveduras & PIC & Diâmetro lesão \\
\hline $11 \mathrm{~A} 2$ & $54,12 \mathbf{a}$ & $1,95 \mathbf{b}$ \\
\hline 7D2 & $51,79 \mathbf{a}$ & $1,95 \mathbf{b}$ \\
\hline $13 \mathrm{E}$ & $47,99 \mathbf{a}$ & $1,90 \mathbf{a}$ \\
\hline $13 \mathrm{~A} 1$ & $47,78 \mathbf{a}$ & $1,85 \mathbf{a}$ \\
\hline 11E2 & $47,14 \mathbf{b}$ & $1,84 \mathbf{a}$ \\
\hline 11E1 & $47,45 \mathbf{b}$ & $1,89 \mathbf{a}$ \\
\hline 11B & $41,01 \mathbf{c}$ & $2,32 \mathbf{b}$ \\
\hline $7 \mathrm{~B}$ & $40,38 \mathbf{c}$ & $2,06 \mathbf{c}$ \\
\hline $11 \mathrm{~F}$ & 39,95 c & $2,20 \mathbf{d}$ \\
\hline 15 & $39,11 \mathbf{c}$ & $2,14 \mathbf{c}$ \\
\hline 40 & $37,84 \mathbf{c}$ & $2,16 \mathbf{d}$ \\
\hline $22 \mathrm{~A}$ & $37,42 \mathbf{d}$ & $2,02 \mathbf{c}$ \\
\hline 35 & $37,42 \mathbf{d}$ & $2,22 \mathbf{d}$ \\
\hline 31 & $35,94 \mathbf{d}$ & $2,13 \mathbf{c}$ \\
\hline 18 & $34,03 \mathbf{d}$ & $2,10 \mathbf{c}$ \\
\hline Testemunha & $00,00 \mathbf{e}$ & $2,91 \mathbf{c}$ \\
\hline Média Geral & 2,84 & 2,10 \\
\hline CV (\%) & 8,65 & 12,14 \\
\hline
\end{tabular}

Médias seguidas pela mesma letra nas colunas não diferem entre si pelo teste de Scott-Knott a 5\% de probabilidade.

Grande parte dos isolados de leveduras utilizados foram identificados como sendo do gênero Rhodotorula, sendo neste caso, encontrada as espécies $R$. minuta, $R$. aurantiaca e $R$. glutinis (Tabela 2). Entretanto, também foram identificadas as espécies Brettanomyces custersianus, Debaryomyces etchellsii, Kluyveromyces lactis, Candida kefyr e Debaryomyces yamadae entre os isolados testados (Tabela2). 
Tabela 2. Identificação das leveduras utilizadas no experimento de controle biológico de Colletotrichum sp. por meio de características morfológicas, fisiológicas e bioquímicas.

\begin{tabular}{lccc}
\hline Registro & Espécie & Coloração & Hospedeiro \\
\hline $11 \mathrm{~A} 2$ & Rhodotorula minuta & Pigmentada & Pimentão \\
$11 \mathrm{E} 1$ & Rhodotorula aurantiaca & Pigmentada & Pimentão \\
31 & Rhodotorula aurantiaca & Pigmentada & Pimentão \\
40 & Rhodotorula aurantiaca & Pigmentada & Pimentão \\
$11 \mathrm{E} 2$ & Rhodotorula glutinis & Pigmentada & Pimentão \\
$13 \mathrm{~A} 1$ & Rhodotorula glutinis & Pigmentada & Pimentão \\
$13 \mathrm{E}$ & Rhodotorula glutinis & Pigmentada & Pimentão \\
15 & Rhodotorula glutinis & Pigmentada & Pimentão \\
$22 \mathrm{~A}$ & Rhodotorula glutinis & Pigmentada & Pimentão \\
35 & Brettanomyces custersianus & Não Pigmentada & Pimentão \\
18 & Debaryomyces etchellsii & Não pigmentada & Pimentão \\
$7 \mathrm{~B}$ & Kluyveromyces lactis & Não Pigmentada & Pimentão \\
$7 \mathrm{D}_{2}$ & Candida kefyr & Não Pigmentada & Pimentão \\
$11 \mathrm{~F}$ & Debaryomyces yamadae & Não Pigmentada & Pimentão \\
$11 \mathrm{~B}$ & Debaryomyces yamadae & Não Pigmentada & Pimentão \\
\hline
\end{tabular}

A taxonomia convencional de leveduras, baseada em caracteres morfológicos, bioquímicos e fisiológicos (KURTZMAN et al., 2011) nem sempre alcança resultados conclusivos. Dessa forma, para que a identificação seja segura, além dos métodos convencionais, deve-se lançar mão de métodos moleculares, tais como a amplificação de regiões conservadas do genoma via reação da polimerase em cadeia (PCR) (LANDELL, 2009).
No presente trabalho, a identificação das leveduras por meio de características morfológicas, fisiológicas e bioquímicas (Tabela 2) confere com a identificação realizada por taxonomia molecular (Tabela 3), sendo os isolados 13E e 13A1, que obtiveram as melhores respostas no controle do fitopatógeno tanto in vitro quanto in vivo pertencentes à espécie Rhodotorula glutinis.

Tabela 3. Tamanhos de fragmentos resultantes de digestão dos produtos de amplificação da região ITS do rDNA com a enzima Hinf I e identificação das leveduras obtidas de frutos de pimentão.

\begin{tabular}{clc}
\hline Levedura & \multicolumn{1}{c}{ Espécie } & Hinf $\mathbf{I}$ \\
\hline $11 \mathrm{~A} 2$ & Rhodotorula minuta & $340+225+75$ \\
$11 \mathrm{E} 1$ & Rhodotorula glutinis & $340+225+75$ \\
$11 \mathrm{E} 2$ & Rhodotorula glutinis & $340+225+75$ \\
$13 \mathrm{~A}_{1}$ & Rhodotorula glutinis & $340+225+75$ \\
$13 \mathrm{E}$ & Rhodotorula glutinis & $340+225+75$ \\
\hline
\end{tabular}

Inúmeras leveduras têm sido identificadas e utilizadas em frutos e vegetais para controle de doenças de pós-colheita (SHARMA et al., 2009). Dentre estas leveduras, o gênero Candida abriga um grande número de espécies antagonistas como a Candida sake utilizada no controle de Penicillium expansum em maçã (MORALES et al., 2008) e em pêra (TORRES et al., 2006); Candida oleophila utilizada em citros controlando Penicillium italicum e $P$. digitatum (LAHLALI et al., 2005) e em banana para o controle de Colletotrichum musae (LASSOIS et al., 2008). No entanto, outras espécies mostraramse eficientes no controle de diversas patologias póscolheita, como a levedura Pichia guilliermondii, que tem sido relatada no controle da antracnose em pimenta causada por Colletotrichum capsici (CHANCHAICHAOVIVAT et al. 2008), no controle de Botrytis cinerea em nectarina, pêssego e tomate (TIAN et al., 2002; SALIGKARIAS et al., 2002) e no controle de Penicillium italicum em laranjas (LAHLALI et al., 2011).

Diversos trabalhos relatam a eficácia de $R$. glutinis no controle de doenças em pós-colheita, como no controle de podridões em frutos de maçãs causadas por Botrytis cinerea e Penicillium expansum (ZHANG et al., 2009a; LI et al., 2011), em combinação com metil jasmonato (MeJA) no controle da podridão cinzenta causada por $P$. expansum (ZHANG et al., 2009b); no controle da podridão negra pós-colheita em abacaxi causada por 
Ceratocystis paradoxa (REYES et al., 2004); em combinação com ácido salicílico no controle da podridão pós-colheita em morango causado por Rhizopus stolonifer (ZHANG et al., 2010a) e Botrytis cinerea (ZHANG et al., 2007; Zhang et al., 2010b; Ge et al., 2010), no controle de podridões verde ou bolor verde de laranjas causadas por Penicillium digitatum (ZHENG et al., 2005) e integrado com água quente no controle de podridões em pêras causadas por Penicillium expansum e $B$. cinerea (ZHANG et al., 2008a; ZHANG et al., 2008b)

O presente estudo, bem como os inúmeros exemplos citados acima, demonstram a eficácia de $R$. glutinis no controle de doenças em pós-colheita. Somado a isso, Zhang et al. (2009a) observaram que o tratamento com $R$. glutinis não afetou os parâmetros de qualidade pós-colheita de maçãs, como perda de massa, firmeza, sólidos solúveis totais (SST), ácido ascórbico (AA), e acidez titulável (AT).

As leveduras podem atuar reduzindo o crescimento e desenvolvimento de fungos fitopatogênicos por meio de diversos mecanismos, como a competição por espaços e nutrientes, indução de resistência na planta hospedeira, parasitismo, produção de enzimas extracelulares, produção de antibióticos, interferência nos fatores de patogenicidade, sendo que prováveis mecanismos diferentes de controle atuem em sinergismo durante a interação antagônica (PUNJA; UTKHEDE, 2003).

Embora os mecanismos de ação dos antagonistas aqui avaliados não tenham sido determinados na presente pesquisa, supõe-se que o sucesso de $R$. glutinis no controle da antracnose do pimentão pode ser devido: a capacidade da levedura em produzir enzimas como as pectinases, quitinases e glucanases (SARAVANAKUMAR et al. 2009; BAUERMAISTER et al. 2010), responsáveis pela despolimerização da parede celular de determinados fungos fitopatogênicos, bem como pela competição por nutrientes (CASTORIA et al. , 1997), uma vez que as leveduras são hábeis, principalmente, na colonização e competição por espaços e nutrientes na superfície de frutos e folhas (MCLAUGHLIN et al.,1990; FILONOW, 1998).

A utilização de $R$. glutinis no controle da antracnose do pimentão pode ser considerada uma alternativa promissora aos fungicidas sintéticos químicos, uma vez que apesar da eficácia obtida não ser tão alta quando comparada com a utilização de fungicidas, seu uso pode prevenir o aparecimento de resistência de fungos fitopatogênicos, tornando o controle biológico uma medida mais eficaz. Além disso, as leveduras não são produtoras de antibióticos ou outros metabólitos secundários tóxicos e, portanto, ditos seguros como agentes de biocontrole de fitopatógenos. Estes fatores contribuem para aceitação de frutos e vegetais tratados com este tipo de produto biológico, uma vez que normalmente são consumidos in natura.

Embora novas investigações sejam necessárias para elucidar o mecanismo de ação destas leveduras, os resultados deste estudo demonstram o potencial de aplicação destes isolados como agentes biológicos para a proteção em póscolheita de pimentão contra Colletotrichum $s p$.

\section{AGRADECIMENTOS}

Agradecemos ao Conselho Nacional de Desenvolvimento Científico e Tecnológico (CNPq) pela concessão da bolsa de iniciação científica.

\begin{abstract}
Considering the losses caused by post-harvest anthracnose in sweet pepper chili and ineffectiveness of control measures currently used, this study had the objective of evaluate the antagonistic potential in vitro and in vivo of fifteen isolates of yeast to Colletotrichum sp., the causal agent of anthracnose on pepper. By calculating the percentage growth inhibition of the fungus treatment compared to the control tests in vitro and determining the size of lesions via the measurement of lesion length in both directions diametrically affixed in vivo tests. Yeasts who obtained the best result in controlling anthracnose were identified by characteristic macroscopic, microscopic, physiological, biochemical and molecular taxonomy. In this study, the yeast isolates 13E and 13A1, which obtained the best results in controlling the pathogen both in vitro and in vivo of the species Rhodotorula glutinis.
\end{abstract}

KEYWORD: Colletotrichum sp. Postharvest disease. Biological control.

\title{
REFERÊNCIAS
}

AZEVEDO, C. P.; CAFÉ FILHO, A. C.; HENZ, G. P.; REIS, A. Recomendações de manejo da antracnose do pimentão e das pimentas. Brasília: Embrapa Hortaliças, 2006. 4 p. (Embrapa Comunicado Técnico, 35). 
BARNETT, J. A. Yeast, Characteristics and Identification, 4th ed. Cambridge: Cambridge University Press, 2000. 811p.

BAUERMEISTER, A.; REZENDE, M. I.; GIESE, E. C.; DEKER, F. H.; BARBOSA, A. M. $\beta$-1,3-glucanases fúngicas: produção e aplicações biotecnológicas. Semina, Londrina, v. 31, n. 1, p. 75-86, 2010.

BETTIOL, W. Controle biológico de doenças de plantas. Jaguariúna: EMBRAPA/CNPDA, 1991. 388p.

CASTORIA, R.; DE CURTIS, F.; LIMA, G.; DE CICCO, V. b-1,3-glucanase activity of two saprophytic yeasts and possible mode of action as biocontrol agents against postharvest diseases. Postharvest Biology and Technology, Washington, v. 12, n. 3, p. 293-300, 1997. http://dx.doi.org/10.1016/S0925-5214(97)00061-6

CHANCHAICHAOVIVAT, A.; RUENWONGSA, P.; PANIJPAN, B. Screening and identification of yeast strains from fruits and vegetables: Potential for biological control of postharvest chilli anthracnose (Colletotrichum capsici). Biological Control, Orlando, v. 42, n. 3, p. 326-335, 2007.

DROBY, S.; WISNIEWSKI, M.; MACARISIN, D.; WILSON, C. Twenty years of postharvest biocontrol research: is it time for a new paradigm? Postharvest Biology and Technology, Amsterdam, v. 52, n. 2, p. 137145, 2009. http://dx.doi.org/10.1016/j.postharvbio.2008.11.009

FILONOW, A. B. Role of competition for sugars by yeast in the biocontrol of gray mold of apple. Biocontrol Science and Technology, Oxford,, v. 8, n. 2. p. 243-256, 1998. http://dx.doi.org/10.1080/09583159830315

FRAVEL, D. R. Commercialization and implementation of biocontrol. Annual Review of Phytopathology, Palo Alto, v. 43, n. 1, p. 337-359, 2005. http://dx.doi.org/10.1146/annurev.phyto.43.032904.092924

GE, L., ZHANG , H., CHEN, K., MA, L., XU, Z. Effect of chitin on the antagonistic activity of Rhodotorula glutinis against Botrytis cinerea in strawberries and the possible mechanisms involved. Food Chemistry, Reading, v. 120, n. 2, p. 490-495, 2010. http://dx.doi.org/10.1016/j.foodchem.2009.10.042

GHINI, R.; KIMATI, H. Resistência de fungos a fungicidas. Jaguariúna: Embrapa Meio Ambiente, 2000. 78 p.

IRTWANGE, S. V. Application of biological control agents in pre- and postharvest operation. Agricultural Engineering International, Hokkaido, v. 8, n. 3, p. 1-12, 2006.

JANISIEWICZ, W. J., KORSTEN, L. Biological control of postharvest diseases of fruits. Annual Review of Phytopathology, Palo Alto, v. 40, n. 2, p. 411-444, 2002.

http://dx.doi.org/10.1146/annurev.phyto.40.120401.130158

KREGER VAN RIJ, N. J. W. The yeasts: a taxonomic study. 3. Ed. Amsterdam: Elsevier Science Publising, 1984. 1082p.

KUROZAWA, C.; PAVAN, M. A.; KRAUSE-SAKATE, R. Doenças das solanáceas. In: KIMATI, H. et al. (Eds.). Manual de fitopatologia: doenças das plantas cultivadas. 4. ed. São Paulo: Agronômica Ceres, 2005, v. 2, cap. 65, p. 589-596.

KURTZMAN, C. P.; FELL, J. W.; BOEKHOUT, T. The Yeasts, a taxonomic study. Ed. Amsterdam: Elsevier Science Publieshers, v. 2, 2011. 1062 p.

LACAZ, C. S. et al. Tratado de micologia médica. 9ed. São Paulo, SP: Sarvier, 2002.1104p.

LAHLALI, R.; HAMADI, Y.; GUILLI, M. E.; JIJAKLI, M. H. Efficacy assessment of Pichia guilliermondii strain Z1, a new biocontrol agent, against citrus blue mould in Morocco under the influence of temperatura and relative humidity. Biological Control, Orlando, v. 56, n. 3, p. 217-224, 2011. 
LAHLALI, R.; SERRHINI, M. N.; JIJAKLI, M. H. Development of a biological control method against postharvest diseases of citrus fruit. Communications on Agriculture and Applied Biological Sciences, Ghent, v. 70, n. 2, p. 47-58, 2005. http://dx.doi.org/10.1016/j.biocontrol.2010.12.001

LANDELL, M. F. Caracterização genética e avaliação da diversidade de leveduras associadas a bromélias no parque de Itapuã-Viamão/RS. Porto Alegre, 2009. 187p.

LASSOIS, L.; De BELLAIRE, L.; JIJAKLI, M. H. Biological control of crown rot of bananas with Pichia anómala strain K and Candida oleophila strain O. Biological Control, Orlando, v. 45, n. 3, p. 410-418, 2008. http://dx.doi.org/10.1016/j.biocontrol.2008.01.013

LI, R., ZHANG, H., LIU, W., ZHENG, X. Biocontrol of postharvest gray and blue mold decay of apples with Rhodotorula mucilaginosa and possible mechanisms of action. International Journal of Food Microbiology, Amsterdam, v. 146, n. 2, p. 151-156, 2011. http://dx.doi.org/10.1016/j.ijfoodmicro.2011.02.015

LOPES, C. A.; ÁVILA, A. C. Doenças do pimentão: diagnose e controle. Brasília: Embrapa Hortaliças, 2003. $96 \mathrm{p}$.

MARI, M.; MARTINI, C.; GUIDARELLI, M.; NERI, F. Postharvest biocontrol of Monilinia laxa, Monilinia fructicola and Monilinia fructigena on stone fruit by two Aureobasidium pullulans strains. Biological Control, Orlando, v. 60, n. 2, 2012.

McLAUGHLIN, R. J.; WISNIEWSKI, M. E.; WILSON, C. L.; CHALUTZ, E. Effect of inoculum concentration and salts solutions on biological control of postharvest diseases of apple with Candida sp. Phytopathology, Palo Alto, v. 80, n. 5, p. 456-461, 1990. http://dx.doi.org/10.1094/Phyto-80-456

MORALES, H.; SANCHIS, V.; USALL, J.; RAMOS, A. J.; MARÍN, S. Effect of biocontrol agents Candida sake and Pantoea agglomerans on Penicillium expansum growth and patulin accumulation in apples.

International Journal of Food Microbiology, Amsterdam, v. 122, n. 3, p. 61-67, 2008. http://dx.doi.org/10.1016/j.ijfoodmicro.2007.11.056

PUNJA, Z. K.; UTKHEDE, R. S. Using fungi and yeasts to manage vegetable crop diseases. Trends in Biotechnology, Oxford, v. 21, n. 9, p. 400-407, 2003. http://dx.doi.org/10.1016/S0167-7799(03)00193-8

QING, F.; SHIPING, T., Postharvest biological control of Rhizopus rot of nectarine fruits by Pichia membranefaciens. Plant Disease, Saint Paul, v. 84, n. 11, p. 1212-1216, 2000.

REYES, M. E. Q.; ROHRBACH, K. G.; PAULL, R. E. Microbial antagonists control postharvest black rot of pineapple fruit. Postharvest Biology and Technology, Amsterdam, v. 33, n. 2, p. 193-203, 2004. http://dx.doi.org/10.1016/j.postharvbio.2004.02.003

SALIGKARIAS, I. D.; GRAVANIS, F. T.; EPTONA, H. A. S. Biological control of Botrytis cinerea on tomato plants by the use of epiphytic yeasts Candida guilliermondii strains and US 7 and Candida Oleophila strarin I182: II. A study on mode of action. Biological Control, Orlando, v. 25, n. 2, p. 151-161, 2002. http://dx.doi.org/10.1016/S1049-9644(02)00052-X

SARAVANAKUMAR, D.; SPADARO, D.; GARIBALDI, A.; GULLINO, M. I. Detection of enzymatic activity and partial sequence of a chitinase gene in Metschnikowia pulcherrima strain MACH1 used as postharvest biocontrol agent. European Journal Plant Pathology, Dordrecht, v. 123, n. 4, p. 183-193, 2009. http://dx.doi.org/10.1007/s10658-008-9355-5

SHARMA, R. R.; SINGH, D.; SINGH, R. Biological control of postharvest diseases of fruits and vegetables by microbial antagonists: A review. Biological Control, Orlando, v. 50, n. 3, p. 205-221, 2009.

http://dx.doi.org/10.1016/j.biocontrol.2009.05.001 
TIAN, S. P.; FAN, Q.; XU, Y.; QIN, G. Z.; LIU, H. B. Effect of biocontrol antagonists applied in combination with calcium on the control of postharvest diseases in different fruit. Bulletin-OILB/SROP, Dijon, v. 25, n. 2, p. 193-196, 2002.

TORRES, R.; TEIXIDO, N.; VINAS, I.; CASALINI, L.; GIRAUD, M.; USALL, J. Efficacy of Candida sake CPA-1 formulation for controlling Penicillium expansum decay on pome fruit from different Mediterranean regions. Journal of Food Protection, Des Moines, v. 69, n. 3, p. 2703-2711, 2006.

TOZZE JR., H. J.; MELLO, M. B. A.; MASSOLA JR., N. S. Caracterização morfológica e fisiológica de isolados de Colletotrichum sp. causadores de antracnose em solanáceas. Summa Phytopathologica, Botucatu, v. 32, n. 1, p. 71-79, 2006.

VALDEBENITO-SANHUEZA, R. M. V. Leveduras para o biocontrole de fitopatógenos. In: MELO, I. S.; AZEVEDO, J. L. (Ed.). Controle biológico. Jaguariúna: Embrapa Meio Ambiente, 2000, v. 3, cap. 2, p. 41-56.

XAVIER FILHA, M. S.; MICHEREFF, S. J. Antracnose do pimentão. Recife: Universidade Federal Rural de Pernambuco, 2006. 2p. (Manejo de Doenças de Hortaliças. Informativo Técnico 1).

ZHANG, H. Y., MA, L., JIANG, S., LIN, H., ZHANG X., GE, L., XU, Z. Enhancement of biocontrol efficacy of Rhodotorula glutinis by salicyclic acid against gray mold spoilage of strawberries. International Journal of Food Microbiology, Amsterdam, v. 141, n. 1, p. 122-125, 2010a.

http://dx.doi.org/10.1016/j.ijfoodmicro.2010.04.022

ZHANG, H. Y., WANG, L., DONG, Y., JIANG, S., CAO, J. AND MENG, R. J. Postharvest biological control of gray mold decay of strawberry with Rhodotorula glutinis. Biological Control, Orlando, v. 40, n. 2, p. 287 292, 2007. http://dx.doi.org/10.1016/j.biocontrol.2006.10.008

ZHANG, H. Y.; MA, L.; TURNER, M.; XU, H.; ZHENG, X.; DONG, X.; JIANG, S. Salicylic acid enhances biocontrol efficacy of Rhodotorula glutinis against postharvest Rhizopus rot of strawberries and the possible mechanisms involved. Food Chemistry, Reading, v. 122, n. 3, p. 577-583, 2010 b.

http://dx.doi.org/10.1016/j.foodchem.2010.03.013

ZHANG, H.Y., WANG, L.; S DONG, Y.; ZHENG, X. D. Integrated control of postharvest blue mold decay of pears with hot water treatment and Rhodotorula glutinis Postharvest Biology and Technology, Amsterdam, v. 49, n. 2, p. 308-313, 2008.

ZHANG, H. Y.; MA, L.; Turner, M.; Xu, H.; Ying Dong a, Song Jiang a. Methyl jasmonate enhances biocontrol efficacy of Rhodotorula glutinis to postharvest blue mold decay of pears. Food Chemistry, Reading, v. 117, n. 3, p. 621-626, 2009a. http://dx.doi.org/10.1016/j.foodchem.2009.04.054

ZHANG, H. Y.; MA, L.; WANG, L., Jiang, S.; Dong, Y.; Zheng, X. Biocontrol of gray mold decay in peach fruit by integration of antagonistic yeast with salicylic acid and their effects on postharvest quality parameters. Biological Control, Orlando, v. 47, n. 1, p. 60-65, 2008. http://dx.doi.org/10.1016/j.biocontrol.2008.06.012

ZHANG, H. Y.; WANG, L.; MA, L.; DONG, Y.; JIANG, S.; XU, B.; ZHENG, X. Biocontrol of major postharvest pathogens on apple using Rhodotorula glutinis and its effects on postharvest quality parameters. International Journal of Food Microbiology, Amsterdam, v. 126, n. 1, p. 167-171, 2009b.

ZHENG, X. D., ZHANG, H. Y., SUN, P. Biological control of postharvest green mold decay of oranges by Rhodotorula glutinis. European Food Research and Technology, Germany, v. 220, n. 2, p. 353-357, 2005. http://dx.doi.org/10.1007/s00217-004-1056-5 